\title{
Prospects for genetic hearing loss screening: 35delG mutation tracking in a newborn population
}

\author{
Vânia B. Piatto, ${ }^{1}$ Camila A. Oliveira, ${ }^{2}$ Fabiana Alexandrino, ${ }^{2}$ \\ Carla J. Pimpinati, ${ }^{3}$ Edi L. Sartorato ${ }^{4}$
}

\begin{abstract}
Objectives: To investigate the prevalence of the 35delG mutation in a newborn population, with specific molecular testing, and to evaluate the prospects for genetic neonatal screening for hearing impairment.

Population and method: 233 newborn were evaluated at the Hospital de Base de São José do Rio Preto, SP, for molecular analysis of the 35delG mutation in the connexin 26 gene, with the reaction technique in allele-specific polymerase chain reaction, after genomic DNA extraction from umbilical cord blood.

Results: Five heterozygotes were identified, obtaining a prevalence of $2.24 \%$ of 35 delG mutation carriers in the study population.

Conclusion: Using the molecular test allowed for the identification of the 35delG mutation in the study population with the possibility of being used as a complement to neonatal audiometric screening as being simple, fast, and easily to perform with low costs.
\end{abstract}

J Pediatr (Rio J). 2005;81(2):139-42: 35delG mutation, molecular analysis, hearing impairment, neonatal screening.

\section{Introduction}

Due to its high frequency and to its clinical impact, the early identification of hearing loss has become an important public health goal. Neonatal screening was recommended by the National Institute of Health and Joint Committee on Infant Hearing Screening for the implementation of electrophysiological tests such as evoked otoacoustic emissions and brainstem auditory evoked response. ${ }^{1,2}$ Along with the technological improvements in the diagnosis of hearing loss, recent and continuous advances in the field of molecular genetics have increasingly allowed for the

1. PhD. Pediatrician. Professor, Department of Anatomy, Medicine School of São José do Rio Preto (FAMERP), SP, Brazil.

2. Biomedical professional. PhD student, Universidade Estadual de Campinas (UNICAMP), SP, Brazil.

3. Undergraduate student, Phonoaudiology School, UNICAMP, SP, Brazil.

4. PhD. Researcher, Center of Molecular Biology and Genetic Engineering, UNICAMP, SP, Brazil.

Manuscript received Sep 01 2004, accepted for publication Nov 242004

Suggested citation: Piatto VB, Oliveira CA, Alexandrino F, Pimpinati CJ, Sartorato EL. Prospects for genetic hearing loss screening: 35delG mutation tracking in a newborn population. J Pediatr (Rio J). 2005;81:139-42. identification of the genes responsible for the inherited form of this disorder and, consequently, for its early detection. ${ }^{3,4}$

Sensorineural hearing loss affects one in every 1,000 newborns, and $60 \%$ of the cases may be attributed to genetic factors, whereas the remaining $40 \%$ has the widest variety of etiologies in industrialized countries. Among genetic causes, syndromic hereditary forms account for $30 \%$ of hearing loss in children, while the non-syndromic forms affect around 70\% of the population. 5

In 1994, the first autosomal recessive non-syndromic deafness locus (DFNB1) was identified on the long arm of chromosome $13(13 q)^{6}$ and, in 1997, connexin 26 gene (Cx26) or gap junction beta-2 protein (GJB2) was detected on chromosome $13 q 11-12 .{ }^{7}$ In the inner ear, Cx26 plays a crucial role in the regulation of cochlear homeostasis and in the production of the endocochlear potential. 8 Therefore, mutations in the Cx26 gene cause a structural and functional defects in these gap junctions, leading to persistently high intracellular potassium concentration; this damages the mechanism that allows the quick response of ciliated cells to new auditory stimuli, consequently resulting in hearing loss. ${ }^{9}$ 
Among the mutations in the $\mathrm{C} \times 26$ gene described so far, which cause DFNB1, a particular mutation and the first one described, the 35delG mutation accounts for most of the mutant alleles (60-85\%) in the Mediterranean European population. ${ }^{10}$ However, around 10 to $42 \%$ of patients with hearing loss have mutations in the $\mathrm{C} \times 26$ gene in only one allele, despite the fact that most mutations have a recessive trait. ${ }^{11}$ In several

European countries, the prevalence of the $35 \mathrm{delG}$ mutation, in normal-hearing individuals, has been estimated to range from 2 to $4 \% .{ }^{10}$

The 35delG mutation arises from the deletion of a guanine (G) from a six-guanine stretch, at nucleotide positions 30 to 35 , in the $C \times 26$ coding region, resulting in premature stop codon mutations, at nucleotide position 38 , with a consequent frameshift and a stop at codon 13, triggering the synthesis of an incomplete polypeptide, with 12 instead of 226 amino acids. ${ }^{12}$

In developing countries, few studies have been carried out to assess the prevalence of hereditary hearing loss. In Brazil, a prevalence of $0.9 \%$ was described in carriers of the 35 delG mutation, that is, $1: 103$ heterozygotes in a neonatal screening. ${ }^{13}$ In another study, now with hearing impaired patients, the 35 delG mutation was identified in $84.2 \%$ of the alleles. ${ }^{14}$

The aim of the present study was to investigate the prevalence of the $35 \mathrm{del}$ mutation, using an allelespecific polymerase chain reaction (AS-PCR) in a sample of newborns, and to draw attention to the necessity of neonatal screening for hearing loss.

\section{Patients and methods}

The study was carried out between September 22 and October 10, in 2003, at the Obstetric Unit of Hospital de Base de São José do Rio Preto, state of São Paulo, Brazil. A total of 227 births occurred at the unit, of which four corresponded to monozygotic twins; therefore, the final sample included 223 newborns. After cord clamping, $4 \mathrm{ml}$ of blood was collected from the umbilical cord, and stored in a Vacutainer ${ }^{\circledR}$ tube containing EDTA. This procedure was performed after the mother or couple signed an informed consent form. The study protocol was approved by the local Research Ethics Committee.

The genomic DNA was extracted from the cord blood samples using GFX ${ }^{\mathrm{TM}}$ Genomic Blood DNA Purification Kit (Amersham Pharmacia Biotech Inc. Limited, 2000), according to the manufacturer's instructions; the procedure was performed at the Molecular Biology Laboratory of the School of Medicine of São José do Rio Preto (FAMERP).

For detection of the 35 delG mutation, we used an allelespecific polymerase chain reaction (AS-PCR), ${ }^{15}$ in Applied Biosystems thermal cycler - GeneAmp PCR System 9700, ${ }^{\mathrm{TM}}$ performed at the Center for Molecular Biology and Genetic Engineering of UNICAMP (CBMEG). Three ARMS (amplification-refractory mutation system) primers were synthesized for mutation screening: normal primer (NOR), used to amplify the allele without the 35delG mutation; mutant primer (MUT), to amplify the allele with the $35 \mathrm{del}$ mutation; and the common primer (COM), used as reverse primer, along with NOR or MUT primers used as forward primers. ${ }^{16}$ The oligonucleotide primer sequences and the conditions for the AS-PCR were carried out as described in the literature. ${ }^{15}$ These two reactions (NOR/COM and MUT/COM) allow identifying each sample as normal homozygote (without the 35delG mutation in both alleles), heterozygote, or mutant homozygote (with the $35 \mathrm{del}$ mutation in one or in both alleles, respectively). Control primers A (forward) and B (reverse) were also synthesized for Cx26 gene co-amplification of a portion of the $X Y$ homologous amelogenin gene. These primers were, therefore, used as internal amplification controls. ${ }^{17}$

The AS-PCR products were analyzed by $1.5 \%$ agarose gel electrophoresis, in Tris-Borate-EDTA or TBE $1 \mathrm{X}$ buffer, containing ethidium bromide at $0.5 \mu \mathrm{g} / \mathrm{ml}$, exposed to ultraviolet light in order to confirm that the reaction was successful, and submitted to gel photodocumentation.

\section{Statistical analysis}

One hundred newborns were evaluated in a pilot study with the aim of estimating the proportion ( $p$ ) of hearing loss in the initial sample. After determining this proportion, we defined the final sample size $(n)$ necessary to statistically represent the total population (Np) of newborns during the study period ( $\mathrm{Np}=223$ newborns). The following parameters were used to calculate the size of the final sample $(n)$ : $\mathrm{p}=0.01$ (estimated by the pilot sample); $\mathrm{q}=0.99 ; \mathrm{zc}=3.00$ ( $99.74 \%$ of reliability); $e=0.03$ ( $3 \%$ of estimation error); $\mathrm{Np}=223$ (population size).

$$
\mathbf{n}=\mathbf{z c}^{2} \times \mathbf{p} \times \mathbf{q} \times \mathbf{N}_{\mathrm{p}} / \mathrm{e}^{\mathbf{2}} \times\left(\mathbf{N}_{\mathrm{p}}-\mathbf{1}\right)+\mathrm{zc}^{\mathbf{2}} \times \mathbf{p} \times \mathbf{q}
$$

The results of the study were expressed as percentage values.

\section{Results}

Among 223 newborns, five were heterozygotes, with a prevalence rate of $2.24 \%(1: 44.6)$ of carriers of the 35 delG mutation in the study population. These heterozygotic newborns have undergone regular audiometric testing.

\section{Discussion}

The population of 223 newborns evaluated at the Hospital de Base de São José do Rio Preto, in São Paulo, by molecular analysis of the Cx26 gene, and by the AS-PCR technique, showed a prevalence rate of $2.24 \%(1: 44.6)$ of $35 \mathrm{del}$ mutation. This result and the methodology used are in agreement with previous studies and with those studies described in the literature, including several populations, in which the prevalence of carriers in samples of 53 to 560 normal-hearing newborns, children or adults, ranged from 0\% (USA, Afro-Americans, England, France and Egypt) to $4.4 \%$ (Estonia). ${ }^{18}$ In the State of New York (USA), a 
screening performed in a population of 2,089 newborns revealed a prevalence of $1.29 \%$ of $35 \mathrm{del}$ G mutation. ${ }^{19}$

The relative contribution of the 35 delG mutation to nonsyndromic hearing loss, in different populations, ranged from 0\% (Oman, Korea, Japan) to 7\% (Italy, Spain, Greece), showing the genetic heterogeneity across countries, although some of these studies included a small number of patients, in addition to some differences regarding the screening methods for detection of the mutation. 20-23

In Brazil, the prevalence of carriers of the $35 \mathrm{delG}$ mutation amounted to $0.97 \%$, approximately $1: 103$ heterozygotes, in a screening carried out in 620 newborns in the region of Campinas, state of São Paulo. ${ }^{13}$ The methodology used in the current study was similar to the study carried out in Campinas, so as to maintain the methodological consistency, but some variation was observed in the frequency of alleles containing the $35 \mathrm{del}$ mutation. This fact can be explained by the difference in the sample or maybe because the ethnic composition of the Brazilian population is highly heterogeneous. Several ethnic groups, especially Caucasians and Africans, miscegenated, which results in different prevalence rates across Brazilian regions or even between cities/towns within the same state. ${ }^{24}$ Therefore, a multicenter study is necessary to determine the actual prevalence of the 35 delG mutation in the Brazilian population.

According to the literature, the analyses of the Cx26 gene in patients with hearing loss often show heterozygosis in approximately 10 to $42 \%$ of the cases, despite the fact that most mutations, especially the 35 delG mutation, have a recessive trait. 11,25 The results of the study carried out in patients with non-syndromic neurosensory hearing loss at the Hospital de Base de São José do Rio Preto are in agreement with these data, since the prevalence of $35 \mathrm{del}$ heterozygotes corresponded to $12.12 \% .{ }^{26}$ Other two Brazilian studies found a prevalence of heterozygotic individuals with hearing loss of $6.45^{14}$ and $2.66 \% .27$. The prevalence in both studies was smaller than in the literature, perhaps because of the differences in the sample or due to ethnic and regional characteristics of the Brazilian population, ${ }^{14}$ as previously mentioned.

However, since hearing loss caused by the $35 \mathrm{del}$ G mutation occurs when there is mutation in both alleles (homozygosis), characterizing autosomal recessive inheritance in most cases, a more comprehensive analysis of the Cx26 gene is necessary in order to distinguish heterozygotic patients with hearing loss (prevalence in 10$42 \%$ of the cases) ${ }^{11,25}$ from normal heterozygotes (healthy carriers, that is, individuals with mutation in just one allele, but with normal hearing, whose prevalence is estimated to vary from 2 to $4 \%$ of the population with hearing problems). ${ }^{10}$ These more comprehensive analyses and studies (including the screening of the entire coding and noncoding regions or the screening of $D(G J B 6-D 13 S 1830)$ mutation in the Cx30gene) should investigate the audiometric and clinical characteristics of these individuals. ${ }^{26}$ In case of heterozygotic patients with hearing loss, recent studies have suggested the existence of another mutation in the Cx26 gene, or the co-occurrence of D(GJB6-D13S1830) mutation in the Cx30 gene, which may contribute to the digenic inheritance of hearing loss. 26

These data support the future use of genetic screening tests, such as AS-PCR, for the detection of the 35delG mutation, as occurred in this study, since they allow the identification of healthy carriers, homozygotes or carriers of the 35delG mutation with hearing loss in a large number of cases. These tests can add to the existing neonatal audiometric screening, as they are simple, quick, easily applied and inexpensive. ${ }^{28-30}$ Newborns whose genetic test shows heterozygosis must be submitted to serial follow-up, because they may carry the $35 \mathrm{del}$ mutation and have hearing loss, or may only carry the mutation and have normal hearing, as occurred in this study.

Our conclusion is that this test allowed for the identification of the 35 delGmutation, and that if it is performed immediately after birth, it may help the early differential diagnosis between healthy carriers and children with hearing loss (35delG homozygotes or heterozygotes). In addition, it will provide parents with valuable information about the treatment and prognosis, combined with genetic counseling. ${ }^{30}$ Therefore, it is imperative that there be interest in establishing the prevalence and the types of mutations that cause non-syndromic hearing loss in Brazil, with continuous population-based studies, so that a program of neonatal genetic screening can be implemented throughout Brazil. This program may bring significant reductions in hospital and medical expenses and improvement to public health, providing patients with a better quality of life.

\section{Acknowledgments}

We express our thanks to the parents who gave their consent and allowed the participation of their children in this study. This contribution is extremely important to the improved future of Brazilian children.

Also thanks to our friend and translator, Cecília Meneguette Ferreira, for her invaluable help.

\section{References}

1. National Institutes of Health Consensus Statement. Early identification of hearing impairment in infants and young children. NIH Consens Statement 1993;11:1-24.

2. American Speech-Language-Hearing Association [homepage on the Internet]. Rockville, Maryland: (c)1997-2005 American Speech-Language-Hearing Association [updated 2003, Aug 30; cited 2005 Mar 4]. Joint Committee on Infant Hearing. Year 2000 position statement: principles and guidelines for early hearing detection and intervention programs. [about 27 screens]. Available from: http://www.asha.org/about/legislationadvocacy/federal/ehdi/y2kpstn_stmnt.htm

3. Denoyelle F, Marlin S, Petit C, Garabédian E-N. Surdités neurosensorielles d'origine génétique. Rev Prat. 2000;50:146-9.

4. American College of Medical Genetics. Genetics Evaluation Guidelines for the Etiologic Diagnosis of Congenital Hearing Loss. Genet Med. 2002;4:162-71.

5. Mustafa T, Arnos KS, Pandya A. Advances in hereditary deafness. Lancet. 2001;358:1082-90. 
6. Guilford P, Ben Arab S, Blanchard S, Levilliers J, Weissenbach J, Belkahia A, et al. A non-syndrome form of neurosensory, recessive deafness maps to the pericentromeric region of chromosome 13q. Nat Genet. 1994;6:24-8.

7. Kelsell DP, Dunlop J, Stevens HP, Lench NJ, Liang, JN, Parry G, et al. Connexin 26 mutations in hereditary non-syndromic sensorineural deafness. Nature. 1997;387:80-3.

8. Shibata Y, Kumai M, Nishi K, Nakamura K. Diversity and molecular anatomy of gap junctions. Med Electron Microsc. 2001;34:153-9.

9. Kikuchi T, Adams JC, Miyabe Y, So E, Kobayashi T. Potassium ion recycling pathway via gap junction systems in the mammalian cochlea and its interruption in hereditary nonsyndromic deafness. Med Electron Microsc. 2000;33:51-6.

10. Gasparini P, Rabionet R, Barbujani G, Melchionda S, Petersen M, Brondum-Nielsen $\mathrm{K}$, et al. High carrier frequency of the 35delG deafness mutation in European populations. Eur J Hum Genet. 2000;8:19-23.

11. Wilcox SA, Saunders K, Osborn AH, Arnold A, Wunderlich J, Kelly $\mathrm{T}$, et al. High frequency hearing loss correlated with mutations in the GJB2 gene. Hum Genet. 2000;106:399-405.

12. Rabionet R, Gasparini P, Estivill X. Connexins and Deafness Homepage. 2004; http://www.crg.es/deafness/cx26mut.php.

13. Sartorato EL, Gottardi E, Oliveira CA, Magna LA, AnnichinoBizzacchi JM, Seixas CA, et al. Determination of the frequency of the 35delG allele in Brazilian neonates. Clin Genet. 2000;58:339-40.

14. Oliveira CA, Maciel-Guerra AT, Sartorato EL. Deafness resulting from mutations in the GJB2 (connexin 26) gene in Brazilian patients. Clin Genet. 2002;61:354-8.

15. Scott DA, Kraft ML, Carmi R, Ramesh A, Elbedour K, Yari Y, et al. Identification of mutation on the connexin 26 gene that cause autossomal recessive nonsyndromic hearing loss. Hum Mutat. 1998;11:387-94.

16. Little S. Amplification-refractory mutation system (ARMS) analysis of point mutations. In: Dracopoli NC, Haines JL, Korf $B R$, et al, editors. Current Protocols in Human Genetics. New York, NY: John Wiley \& Sons Inc; 1998. p. 981-9.

17. Antoniadi T, Gronskov K, Sand A, Pampanos A, BrondumNielsen K, Petersen MB. Mutation analysis of the GJB2 (connexin 26) gene by DGGE in Greek patients with sensorineural deafness. Hum Mutat. 2000;16:7-12.

18. Van Laer L, Coucke P, Mueller RF, Caethoven G, Flothmann K, Prasad SD, et al. A common founder for the 35delG GJB2 gene mutation in connexin 26 hearing impairment J Med Genet. $2001 ; 38: 515-8$.

19. Fitzgerald T, Duva S, Ostrer H, Pass K, Oddoux C, Ruben R, et al. The frequency of GJB2 and GJB6 mutations in the New York State newborn population: feasibility of genetic screening for hearing defects. Clin Genet. 2004;65:338-42.
20. Rabionet R, Zelante L, Lopez-Bigas N, D'Agruma L, Melchionda $S$, Restagno $G$, et al. Molecular basis of childhood deafness resulting from mutations in the GJB2 (connexin 26) gene. Hum Genet. 2000;106:40-4.

21. Kenna MA, Wu B-L, Cotanche DA, Korf BR, Rehm HL. Connexin 26 studies in patientes with sensorineural hearing loss. Arch Otolaryngol Head Neck Surg. 2001;127:1037-42.

22. Simsek M, Al-Wardy N, Al-Khayat A, Shanmugakonar M, AlBulushi T, Al-Khabory $M$, et al. Absence of deafness associated connexin 26 (GJB2) gene mutations in the Omani population. Hum Mutat. 2001;18:545-6.

23. Pampanos A, Economides J, Iliadou V, Neou P, Leotsakos P, Voyiatzis, et al. Prevalence of GJB2 mutations in prelingual deafness in the Greek population. Int J Pediatr Otorhinolaryngol. 2002;65:101-8.

24. Oliveira CA, Alexandrino F, Abe-Sandes K, Silva Jr WA, MacielGuerra AT, Magna LA, et al. Frequency of 35delG in the GJB2 gene in samples of Caucasians, Asians and African Brazilians. Hum Biol. 2004; 76:313-6.

25. Stevenson VA, Ito M, Milunsky JM. Connexin-30 deletion analysis in connexin-26 heterozygotes. Genet Test. 2003;7:151-4.

26. Piatto VB, Bertollo EM, Sartorato EL, Maniglia JV. Prevalence of the GJB2 mutations and the del(GJB6-D13S1830) mutation in Brazilian patients with deafness. Hear Res. 2004;196:87-93.

27. Pfeilsticker LN, Stole G, Sartorato EL, Delfino D, Guerra ATM. A investigação genética na surdez hereditária não-sindrômica. Rev Bras Otorrinolaringol. 2004;70:182-6.

28. Green GE, Scott DA, McDonald JM, Woodworth GG, Sheffield VC, Smith RJ. Carrier rates in the midwestern United States for GJB2 mutations causing inherited deafness. JAMA. 1999;281:2211-6.

29. Fernandez-Burriel M, Rodriguez-Quinones F. A simple method of screening for the common connexin-26 gene 35 delG mutation in nonsyndromic neurosensory autosomal recessive deafness. Genet Test. 2003; 7:147-9.

30. Smith RJ, Hone S. Genetic screening for deafness. Pediatr Clin North Am. 2003;50:315-29.

Correspondence:

Vânia Belintani Piatto

Rua Santina Figliagi Ceccato, 450/23-A

CEP 15035-180 - São José do Rio Preto, SP

Brazil

Tel.: + 55 (17) 231.0874

E-mail:vabp@bol.com.br 